\title{
Storage stability of clarified banana juice fortified with inulin and oligofructose.
}

\begin{abstract}
Clarified banana juice fortified with inulin and oligofructose were stored for 8 weeks at 4, 25 and 35C. Changes in physicochemical characteristics ( $\mathrm{pH}$, total soluble solids [TSS], titratable acidity, sucrose, reducing sugars and turbidity), microbial count and sensory quality were determined. No differences were observed for $\mathrm{pH}$ and titratable acidity for all the stored juice samples. However, increase in turbidity was observed in all the juice samples, whereas juice samples stored at $35 \mathrm{C}$ recorded highest increases. Increase in reducing sugars (glucose and fructose) was also observed during storage, particularly at 25 and $35 \mathrm{C}$. TSS values were observed fluctuating for all the samples. No microbial growth was recorded for all the juice samples stored at three different temperatures. Sensory results for taste, flavor and odor revealed no difference until the seventh week of storage; however, the overall acceptability of the juice stored at $4 \mathrm{C}$ was rated highest as compared with juice samples stored at 25 and 35C. Overall, the quality of juice stored at $4 \mathrm{C}$ was rated highest not only for all the sensory characteristics but also less turbidity problem compared with juices stored at 25 and $35 \mathrm{C}$.
\end{abstract}

